\title{
Penilaian Keselamatan Wisata Berdasarkan Parameter Gelombang di Pantai Parigi, Kabupaten Pangandaran Jawa Barat
}

\author{
Ankiq Taofiqurohman* dan Mochamad Rudyansyah Ismail \\ Program Studi Ilmu Kelautan, Fakultas Perikanan dan IImu Kelautan, Universitas Padjadjaran \\ JI. Raya Bandung-Sumedang KM.21, Jatinangor, Jawa barat \\ Email: ankiq109@gmail.com
}

\begin{abstract}
Safety Assessment of Tourism Based on Wave Parameter in Parigi Beach, Kabupaten Pangandaran West Java
\end{abstract}

Parigi Beach is one of the beach tourism destinations in West Java. Parigi Beach is in Kabupaten Pangandaran where is facing directly to the Indian Ocean; hence the beach wave is high and risks for beach tourism activity. Beach hazard in Parigi Beach is frequent on long holiday seasons. The research aim is to assess beach tourism safety based on wave parameters and find out the cause of danger. The result shows that Parigi Beach is an intermediate rhythmic bar and beach, which average of the breaking wave height reaches to 1,87 meter and occur beach cusps formation. The beach safety levels exhibit that low safety condition exists from March to November, while from December to February, the beach condition was categorized as moderate safety for coastal tourism activity. Rip current and shore break as the main factor of hazard beach tourism from January to February, whereas from Maret to December, hazard factors in Parigi Beach was rip current and plunging high wave.

Keywords : Parigi Beach; Safety; Tourism; Wave

\begin{abstract}
Abstrak
Pantai parigi merupakan salah satu tujuan wisata pantai di Jawa Barat. Pantai Parigi berada di Kabupaten Pangandaran yang letaknya berhadapan langsung dengan Samudera Hindia, sehingga gelombang di Pantai Parigi relatif tinggi dan berisiko untuk kegiatan wisata pantai. Kecelakaan wisata pantai di Pantai Parigi sering terjadi saat musim libur panjang. Penelitian ini bertujuan untuk menilai tingkat keselamatan wisata pantai tiap bulan berdasarkan parameter gelombang dan mengetahui faktor penyebab bahaya yang terjadi. Hasil penelitian menunjukan bahwa Pantai Parigi termasuk ke dalam tipe pantai intermediate rhythmic bar and beach dengan tinggi gelombang pecah rata-rata mencapai 1,87 meter serta terdapat jejak gelombang berbentuk busur di pantainya. Untuk tingkat keselamatan wisata pantai, keadaan kurang aman di Pantai Parigi terjadi dari mulai Maret hingga November, sedangkan dari Desember hingga Februari dikategorikan pada situasi cukup aman. Faktor penyebab bahaya wisata pantai adalah Rip current dan shorebreak yang muncul pada bulan Januari dan Februari, sementara pada bulan Maret hingga Desember faktor penyebab bahaya adalah rip current dan gelombang tinggi dengan tipe plunging.
\end{abstract}

Kata kunci : Pantai Parigi; Keselamatan; Wisata; Gelombang

\section{PENDAHULUAN}

Kabupaten Pangandaran merupakan kabupaten baru hasil pemekaran dari Kabupaten Ciamis, Jawa Barat. Secara geografis Kabupaten Pangandaran termasuk kedalam wilayah Pantai Selatan Jawa yang letaknya berhadapan langsung dengan Samudera Hindia. Morfologi pesisir Kabupaten Pangandaran sebagian 
berbentuk teluk sehingga memberikan keuntungan dalam pemanfaatan potensi pantai sebagai kawasan wisata bahari.

Kabupaten Pangandaran mengandalkan pariwisata, terutama wisata pantai, sebagai salah satu sektor unggulan dalam meningkatkan pendapatan daerah (Darusman, 2018). Jumlah kunjungan wisatawan ke Kabupaten Pangandaran mencapai lebih dari empat juta pengunjung dalam rentang waktu 2014 sampai dengan 2016 (Badan Pusat Statistik Kabupaten Ciamis, 2018). Jumlah wisatawan akan mencapai puncaknya pada musim liburan sekolah serta saat tahun baru dan Idul Fitri.

Daya tarik wisata pantai di Pangandaran mengandalkan panorama bentang lahan pesisir dan kegiatan bermain air serta pasir di tepian pantai. Pantai Parigi merupakan salah satu destinasi wisata pantai yang padat akan pengunjung dibandingkan beberapa pantai lainnya di Pangandaran. Pantai Parigi berada di sebelah barat Cagar Alam Pananjung serta berlokasi di dalam teluk (Gambar 1). Secara umum masyarakat sekitar menyebut Pantai Parigi sebagai pantai barat, sedangkan Teluk Pangandaran sebagai pantai timur. Secara geografis, pantai ini terlindung dari energi gelombang yang tidak terlalu besar pada batas kedalaman dan waktu tertentu (Setyawan et al., 2011).

Wisata pantai memiliki risiko kecelakaan relatif tinggi dibandingkan aktifitas wisata di daratan, begitu pula wisata Pantai Parigi.
Menurut Pareira et al. (2004), pantai merupakan elemen lingkungan yang mengekspose bahaya secara langsung terhadap penggunanya. Sedangkan menurut Hartman et al. (2009) bahaya pada wisata pantai terjadi karena interaksi antara wisatawan dengan kondisi morpodinamik dan oseanografi pesisir. Salah satu penyebab terjadinya kecelakaan wisata pantai adalah energi gelombang yang tinggi terutama tipe gelombang pecah plunging dan collapsing. Gelombang pecah plunging memiliki potensi lebih tinggi membentuk rip current dibandingkan tipe gelombang pecah lainnya (Khoirunnisa et al., 2013). Posisi Pantai Parigi yang berhadapan langsung dengan Samudera Hindia sangat memungkinkan terbentuknya rip current yang berbahaya seperti diungkapkan oleh Sandro et al. (2018) yang menyatakan panjang dan lebar dari rip current di Pantai Pangandaran mencapai 300 meter dan 90 meter.

Dinamika pantai seperti inilah yang perlu diperhatikan saat wisatawan melakukan aktivitas di pantai, terutama jika wisatawan yang berkunjung tidak memiliki kemampuan berenang sebagaimana yang dinyatakan oleh Clifford et al. (2018) dan Warton and Brander (2017) bahwa penyebab utama dari kecelakaan wisata pantai adalah tidak terampilnya wisatawan dalam berenang.

Kondisi pantai yang dinamis karena dipengaruhi dinamika laut dan pesisir akan menyebabkan terjadinya perubahan pada gelombang ataupun arus yang terjadi

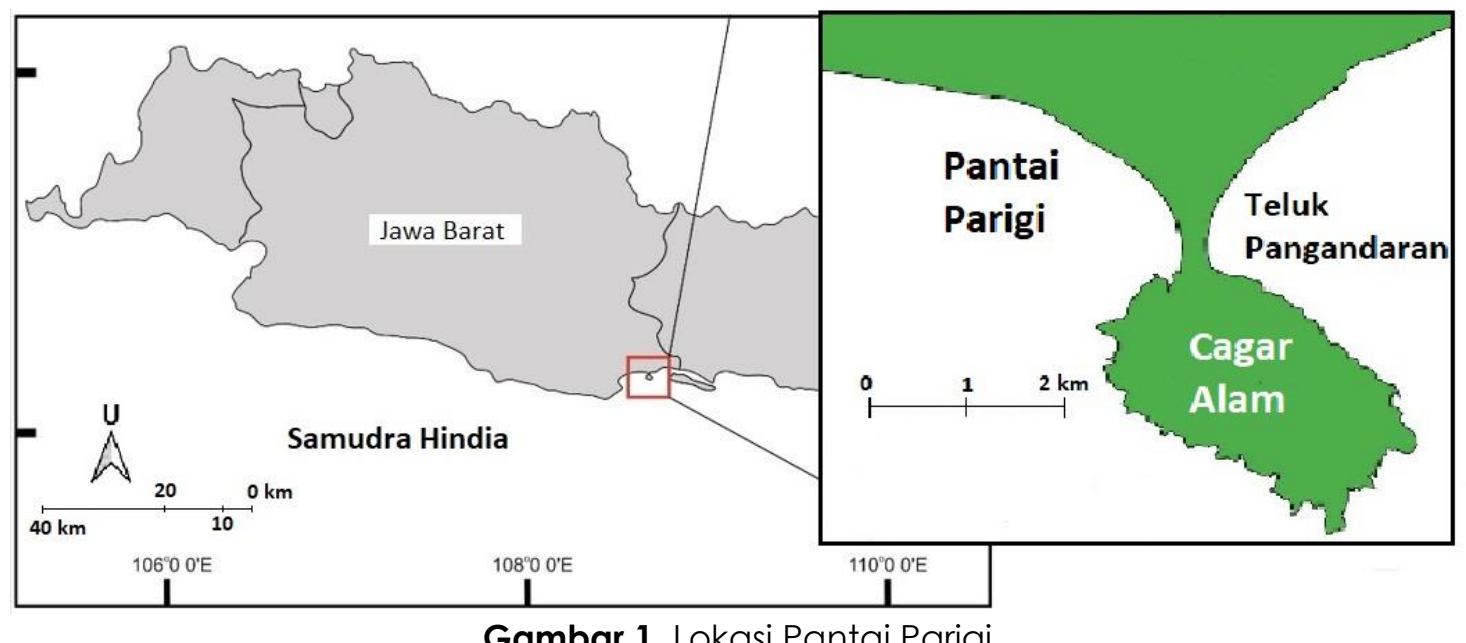

Gambar 1. Lokasi Pantai Parigi 
dipantai dan kondisi tersebut mempengaruhi tingkat keselamatan wisatawan dalam beraktifitas di pantai. Tingkat keselamatan wisata merupakan salah satu alasan yang dapat meningkatkan jumlah kunjungan (Suharto, 2016 dan Tyawati, 2016).

Kecelakaan wisata pantai di Kabupaten Pangandaran sering terjadi karena ketidaktahuan wisatawan terhadap bahaya dinamika pantai bagi keselamatan. Penelitian ini bertujuan untuk menilai tingkat keselamatan wisata pantai tiap bulan berdasarkan parameter gelombang dan mengetahui faktor penyebab bahaya yang terjadi di Pantai Parigi. Patra et al. (2014) mengemukakan bahwa bahwa tinggi gelombang rata-rata bulanan merupakan kriteria utama dalam penentuan tingkat bahaya pantai. Hasil dari penelitian ini diharapkan dapat meminimalisir kecelakaan aktifitas wisata di Pantai Parigi.

\section{MATERI DAN METODE}

Pada penelitian ini, dilakukan beberapa tahapan, diantaranya menentukan parameter oseanografi dan sedimen, meklasifikasikan tipe pantai, mengukur tingkat keselamatan pantai berdasarkan tipe pantai dan tinggi gelombang setiap musim atau bulan. Untuk mengetahui tingkat keselamatan wisata pantai pada penelitian ini, digunakan pendekatan yang dipublikasikan oleh Short and Hogan (1994), yaitu melalui penilaian berdasarkan bentuk pantai dan tinggi gelombang. Dari bentuk pantai dan tinggi gelombangnya, dapat diperkirakan nilai bahaya yang dapat terjadi (Tabel 1). Tinggi gelombang yang digunakan untuk menghitung tingkat keselamatan pantai adalah tinggi gelombang pecah, dikarenakan gelombang pecah adalah gelombang terakhir dengan tinggi maksimum di pantai.

\section{Penentuan tipe pantai dan gelombang pecah}

Bentuk pantai ditentukan dari parameter gelombang, pasut dan jenis sedimen, dengan mengikuti kriteria sebagai berikut (Tabel 2). Perhitungan untuk menentukan klasifikasi tipe pantai menggunakan rumus menurut Short (1996).

Menghitung tinggi gelombang pecah (Hb) menggunakan pendekatan dari Goda (1970) yaitu menentukan tinggi gelombang berdasarkan perbandingan indeks tinggi gelombang pecah dengan kecuraman gelombang pada shoaling Factor Nomogram, sedangkan penentuan jenis gelombang pecah menggunakan klasifikasi bilangan Irribaren.

Tabel 1. Bobot tingkat keselamatan dan faktor bahaya untuk wisata pantai berdasarkan tipe pantai dan tinggi gelombang (Short and Hogan. 1994)

\begin{tabular}{|c|c|c|c|c|c|c|c|c|c|}
\hline \multicolumn{2}{|c|}{$\begin{array}{l}\text { Tinggi gelombang } \\
\text { Tipe pantai }\end{array}$} & $\begin{array}{l}<0,5 \\
(\mathrm{~m})\end{array}$ & $\begin{array}{l}0,5 \\
\text { (m) }\end{array}$ & $\begin{array}{c}1 \\
(\mathrm{~m})\end{array}$ & $\begin{array}{l}1,5 \\
(\mathrm{~m})\end{array}$ & $\begin{array}{c}2 \\
(\mathrm{~m})\end{array}$ & $\begin{array}{l}2,5 \\
(\mathrm{~m})\end{array}$ & $\begin{array}{c}3 \\
(\mathrm{~m})\end{array}$ & $\begin{array}{l}>3 \\
(\mathrm{~m})\end{array}$ \\
\hline \multicolumn{2}{|c|}{ Dissipative } & 4 & 5 & 6 & 7 & 8 & 9 & 10 & 10 \\
\hline \multicolumn{2}{|c|}{ Long Shore Bar Trough } & 4 & 5 & 6 & 7 & 7 & 8 & 9 & 10 \\
\hline \multicolumn{2}{|c|}{ Rhythmic Bar Beach } & 4 & 5 & 6 & 6 & 7 & 8 & 9 & 10 \\
\hline \multicolumn{2}{|c|}{ Transverse Bar Rip } & 4 & 4 & 5 & 6 & 7 & 8 & 9 & 10 \\
\hline \multicolumn{2}{|c|}{ Low Tide Terrace } & 3 & 3 & 4 & 5 & 6 & 7 & 8 & 10 \\
\hline \multicolumn{2}{|c|}{ Reflective } & 2 & 3 & 4 & 5 & 6 & 7 & 8 & 10 \\
\hline \multicolumn{10}{|c|}{ Keterangan: } \\
\hline Bobot & $\begin{array}{c}\text { Tingkat } \\
\text { keselamatan }\end{array}$ & & \multicolumn{7}{|c|}{ Faktor bahaya } \\
\hline $\begin{array}{l}1-3 \\
4-6 \\
7-8 \\
9-10 \\
\end{array}$ & $\begin{array}{l}\text { Aman } \\
\text { Cukup aman } \\
\text { Kurang aman } \\
\text { Tidak aman }\end{array}$ & & & \multicolumn{5}{|c|}{$\begin{array}{c}\text { Kedalaman, Arus yang lemah } \\
\text { Shorebreak } \\
\text { Rip Curent, Shorebreak } \\
\text { Rip Curent, Gelombang tinggi }\end{array}$} & \\
\hline
\end{tabular}


Tabel 2. Klasifikasi tipe pantai

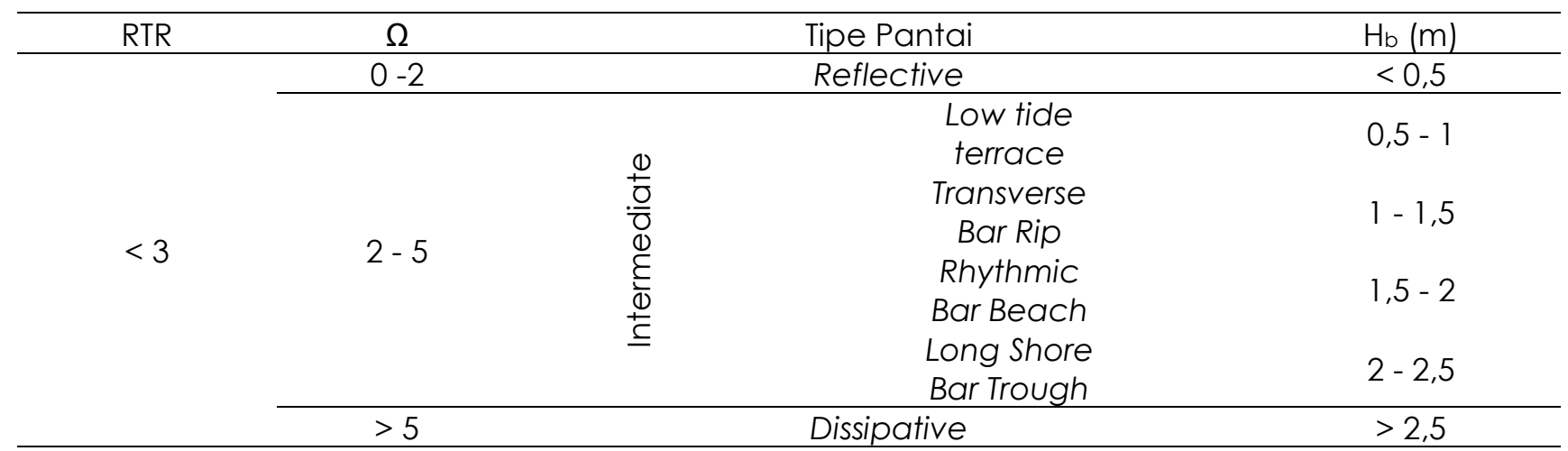

Tabel 3. Klasifikasi tipe gelombang pecah

\begin{tabular}{cc}
\hline Tipe gelombang pecah & Bilangan Iribarren (Ni) \\
\hline Spilling & $\mathrm{Ni}<0,4$ \\
Plunging & $0,4<\mathrm{Ni}<2,3$ \\
Collapsing & $2,3<\mathrm{Ni}<3,2$ \\
Surging & $\mathrm{Ni}>3,2$ \\
\hline
\end{tabular}

Data parameter gelombang yang digunakan untuk menghitung gelombang pecah adalah data parameter gelombang signifikan dari tahun 2013 sampai dengan 2018 yang berasal dari model WaveWatch III. Data hasil pemodelan WaveWatch III dapat merepresentasikan keadaan gelombang di laut dalam (Suciaty, 2018; Sofian and Wijanarto, 2010)

\section{HASIL DAN PEMBAHASAN}

Data parameter oseonografi di beberapa pantai pangandaran relatif sama, kondisi pantainya pun tidak berbeda. Sehingga data yang digunakan pada penelitian ini adalah data dari beberapa penelitian untuk menentukan tipe pantai Parigi (Tabel 4).

Tabel 4. Nilai parameter oseanografi di Pantai Kabupaten Pangandaran

\begin{tabular}{|c|c|c|}
\hline Parameter & $\begin{array}{l}\text { Nilai / } \\
\text { Jenis }\end{array}$ & Sumber \\
\hline $\begin{array}{c}\text { Tunggang } \\
\text { pasut }\end{array}$ & $2,56 \mathrm{~m}$ & Basith (2014) \\
\hline Kemiringan & $10-20^{\circ}$ & $\begin{array}{l}\text { Kusmanto dan } \\
\text { Setyawan (2013) }\end{array}$ \\
\hline Sedimen & coarse & Yudhicara et al. (2013) \\
\hline
\end{tabular}

Tunggang pasut di Pantai parigi sebesar 2,56 m, kemiringan termasuk landai dan jenis sedimen cenderung coarse. Sehingga, Pantai Parigi dikategorikan ke dalam tipe pantai intermediate, sedangkan gelombang pecah rata-rata yaitu sebesar 1,87 meter mengklasifikasikan Pantai Parigi kedalam tipe pantai intermediate rhythmic bar and beach (RBB) (Tabel 5). Pantai dengan karakteristik intermediate RBB, memiliki tinggi gelombang antara 1,5 sampai dengan 2 meter dengan jenis sedimen fine,coarse dan medium.

Pantai intermediate RBB memiliki ciri morfologi cusps pantai yaitu formasi garis pantai dalam pola busur. Cusps pantai dapat dikenali dari jejak swash gelombang berbentuk busur pada pasir pantai. Pada Pantai Parigi keberadaan cusps pantai ditunjukan oleh citra Satelit (Gambar 2). Untuk meminimalisir bahaya pantai tipe intermediate RBB, maka aktifitas wisata sebaiknya dilakukan saat tinggi gelombang dibawah 1,5 meter (Short dan Hogan, 1994).Dari hasil pengolahan data gelombang tiap bulan, didapatkan bobot bahaya, bilangan Iribarren, tingkat keselamatan, dan faktor penyebab bahayanya (Tabel 6). 
Tabel 6. Tingkat keselamatan Pantai Parigi tiap bulan

\begin{tabular}{|c|c|c|c|c|c|}
\hline Bulan & $\begin{array}{l}\mathrm{Hb} \\
(\mathrm{m})\end{array}$ & BB & $\mathrm{Ni}$ & TK & Faktor bahaya \\
\hline Januari & 1,46 & 6 & 0,65 & CA & Rip current dan shorebreak \\
\hline Februari & 1,47 & 6 & 0,60 & CA & Rip current dan shorebreak \\
\hline Maret & 1,62 & 7 & 0,61 & KA & Rip Current dan gelombang tinggi plunging \\
\hline April & 1,77 & 7 & 0,62 & KA & Rip Current dan gelombang tinggi plunging \\
\hline Mei & 1,93 & 7 & 0,62 & KA & Rip Current dan gelombang tinggi plunging \\
\hline Juni & 2,04 & 8 & 0,61 & KA & Rip Current dan gelombang tinggi plunging \\
\hline Juli & 2,12 & 8 & 0,61 & KA & Rip Current dan gelombang tinggi plunging \\
\hline Agustus & 2,15 & 8 & 0,58 & KA & Rip Current dan gelombang tinggi plunging \\
\hline September & 2,21 & 8 & 0,56 & KA & Rip Current dan gelombang tinggi plunging \\
\hline Oktober & 1,68 & 7 & 0,54 & KA & Rip Current dan gelombang tinggi plunging \\
\hline November & 1,76 & 7 & 0,63 & KA & Rip Current dan gelombang tinggi plunging \\
\hline Desember & 1,55 & 6 & 0,60 & CA & Rip Current dan gelombang tinggi plunging \\
\hline
\end{tabular}

Keterangan : BB (Bobot bahaya); TK (Tingkat keselamatan); CA (Cukup aman); KA (Kurang aman)

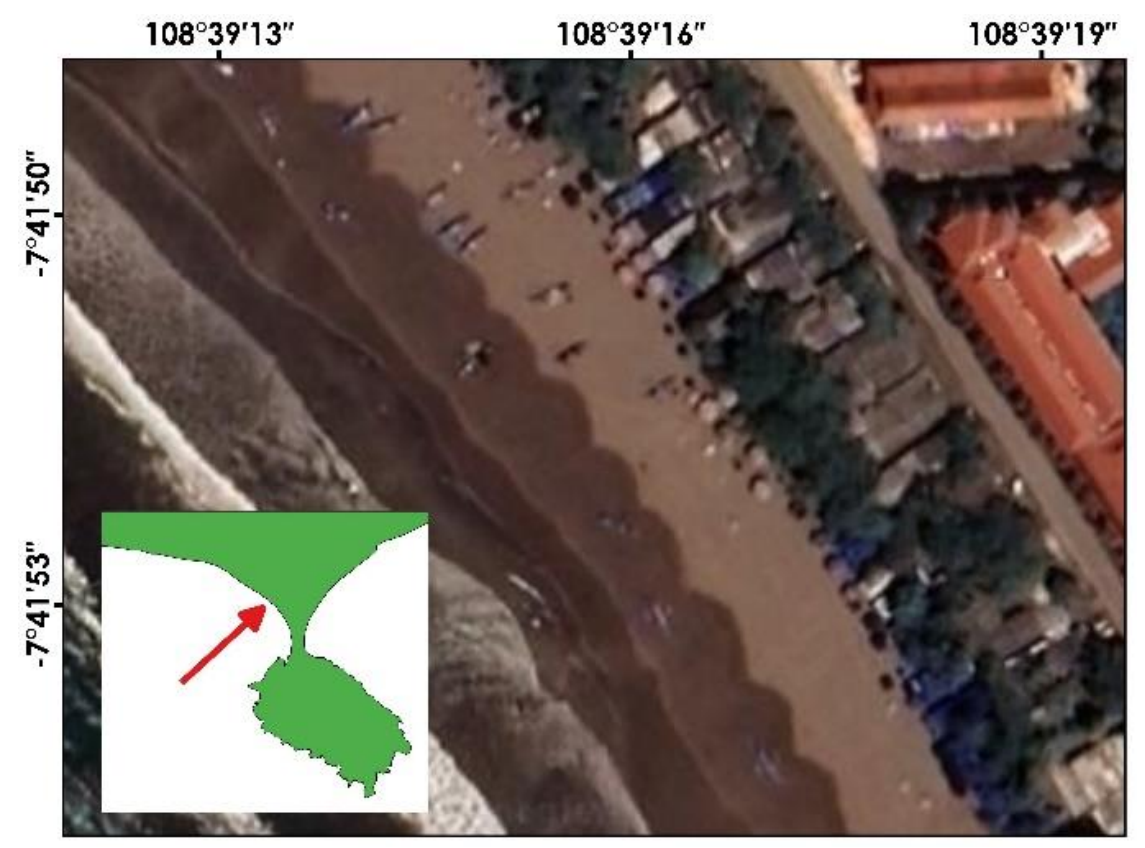

Gambar 2. Jejak swash gelombang berbentuk busur di Pantai Parigi

Hasil perhitungan nilai Iribarren di Pantai Parigi menghasilkan kisaran angka 0,54 sampai dengan 0,63 , sehingga tipe gelombang pecah yang terjadi di Pantai Parigi diklasifikasikan sebagai plunging. Gelombang pecah tipe plunging menjadi salah satu faktor bahaya kegiatan wisata pantai jika memiliki tinggi diatas $1,5 \mathrm{~m}$.

Pada umumnya Pantai Parigi memiliki tingkat keselamatan wisata pantai kurang aman dari bulan Maret hingga November, dengan faktor penyebab bahayanya yaitu rip current dan gelombang tinggi bertipe plunging. Pada bulan Desember, Januari dan Februari Pantai Parigi termasuk kedalam tingkat keselamatan cukup aman. Meskipun bulan Desember termasuk dalam keadaan cukup aman tetapi memiliki faktor penyebab bahaya rip current dan gelombang tinggi plunging, sedangkan bulan Januari dan Februari tidak memiliki kategori faktor bahaya yang berasal dari gelombang tinggi tetapi berasal dari rip current dan shorebreak. 
Tabel 5. Hasil perhitungan untuk menentukan tipe Pantai Parigi

\begin{tabular}{cc}
\hline Parameter & Nilai \\
\hline $\mathrm{Hb}$ & $1,87 \mathrm{~m}$ \\
$\mathrm{Tp}$ & $13,38 \mathrm{~s}$ \\
Ws & $0,066 \mathrm{~m} / \mathrm{s}$ \\
RTR & 1,370 \\
$\Omega$ & 2,120 \\
\hline
\end{tabular}

Tinggi rata-rata gelombang di Pantai Parigi yang mencapai lebih dari 1,5 meter tiap bulan harus diwaspadai saat melakukan kegiatan wisata pantai, sebagaimana hasil penelitian mengenai kecelakaan wisata pantai yang dilakukan oleh Arozarena et al. (2015) di kawasan Karibia, dan Yang et al. (2014) di Korea Selatan menunjukan bahwa tinggi gelombang rata-rata diatas $1,5 \mathrm{~m}$ merupakan penyebab utama terjadinya kecelakaan. Tinggi rata-rata gelombang pecah di Pantai Parigi mencapai puncaknya pada bulan Juni, Juli, Agustus dan September, hal ini dikarenakan pada bulanbulan tersebut merupakan puncak dari rawan gelombang tinggi di Samudera Hindia akibat monsun Australia (Kurniawan et al., 2012).

Menurut McCarrol et al. (2014), tingkat keselamatan wisata pantai dapat dikategorikan berdasarkan tingkatan umur wisatawan. Pada tingkat keselamatan aman, maka semua tingkatan umur memiliki risiko yang rendah terhadap bahaya pantai. Untuk tingkat keselamatan cukup aman, maka bahaya cenderung berisiko untuk anak-anak dan remaja, sedangkan pada tingkat keselamatan kurang aman, risiko bahaya pantai termasuk untuk wisatawan dewasa yang tidak memiliki kemampuan berenang. Untuk keadaan tidak aman, maka risiko kecelakaan berpeluang menimpa seluruh kalangan umur walaupun memiliki kemampuan berenang.

Pantai merupakan area wisata yang terbuka dan pantai dengan energi gelombang yang rendah dikategorikan sebagai pantai yang aman, sehingga direkomendasikan untuk kegiatan wisata keluarga (Hartman et al., 2009). Pantai Parigi yang memiliki tingkat keselamatan cukup dan kurang aman, secara umum dapat direkomendasikan untuk kegiatan wisata keluarga, tetapi dengan pencegahan bahaya dan pengawasan pantai secara intensif. Pencegahan bahaya wisata pantai, dapat dilakukan secara langsung di lokasi melalui upaya-upaya untuk mengurangi risiko kegiatan wisata, seperti penyebaran papan informasi, rambu-rambu keselamatan, penyediaan sarana dan prasarana keselamatan, serta intensitas kehadiran petugas terkait. Pencegahan secara tidak langsung yaitu melalui pendidikan dan kampanye mengenai keselamatan pantai terutama bagi kalangan anak-anak dan remaja. Menurut Woodward et al. (2015), untuk mendapatkan hasil yang optimal dalam pencegahan bahaya pantai, maka kampanye keselamatan untuk anak-anak dan remaja yang disertai peragaan visual mengenai bahaya pantai merupakan cara komunikasi yang paling efektif.

\section{KESIMPULAN}

Pantai Parigi di Kabupaten Pangandaran termasuk kepada tipe pantai intermediate rhythmic bar and beach, dengan karakteristik tinggi gelombang ratarata antara 1,5 sampai dengan 2 meter, memiliki sedimen jenis fine, coarse dan medium serta mempunyai ciri morfologi cusps pantai. Tingkat keselamatan di Pantai Parigi dikategorikan kedalam tipe kurang aman dari bulan Maret hingga November, dengan rip current dan gelombang tinggi bertipe plunging sebagai faktor utama penyebab bahaya wisata pantai. Pada bulan Desember, Januari dan Februari Pantai Parigi memiliki tingkat keselamatan cukup aman, dengan penyebab faktor bahaya yang berbeda. Untuk bulan Desember, faktor bahaya wisata pantai disebabkan oleh rip current dan gelombang tinggi plunging, sedangkan bulan Januari dan Februari faktor bahayanya dikarenakan adanya rip current dan shorebreak. Wisatawan yang paling berisiko terhadap ancaman bahaya wisata di Pantai Parigi adalah pada usia anak-anak dan remaja.

\section{DAFTAR PUSTAKA}

Arozarena, I., Houser, C., Echeverria, A.G. \& Brannstrom, C., 2015, The Rip Current 
Hazard in Costa Rica. Natural Hazards, 77:753-768.

Badan Pusat Statistik [BPS], 2018, Kabupaten Pangandaran Dalam Angka 2018. Ciamis : Badan Pusat Statistik.

Basith, A., 2014, Tantangan Dalam Akuisisi Data Hidrografi di Zona Intertidal untuk Pemetaan Lingkungan Pantai Indonesia Skala 1:10000, Jurnal IImiah Geomatika, 20(2):87-94.

Clifford, K.M., Brander, R.W., Trimble, S., \& Houser, C., 2018. Beach safety knowledge of visiting international study abroad students to Australia. Tourism Management, 69:487-497.

Darusman, A.H., 2018, Kajian Keberadaan Empat Sentral Belanja Di Kabupaten Pangandaran Terhadap Pertumbuhan Minat Belanja Wisatawan, Jurnal Manajemen Resort dan Leisure, 15(1):7986.

Goda, Y.,1970, A Synthesis of Breaker Indices, Japan Society of Civil Engineers, 2(2):227230

Google Earth, 2017, Pangandaran 7.70S 108.650 W, Elevation $431 \mathrm{~m}, \mathrm{CNES} /$ Airbus 2019, http://www.earth.google.com. (diakses : Juni 2019).

Hartman, D., Pick, K. \& Segal, Y., 2009, Onshore Storminess Factor: A New Tool for Regional Beach Hazard Rating and Beach Safety Management, Journal of Coastal Research, 56:807-811

Khoirunnisa, N., Hariyadi \& Rifai, A., 2013. Pemetaan Zona Rip Current Sebagai Upaya Peringatan Dini Untuk Bahaya Pantai (Lokasi Kajian : Pantai Kuta Bali), Jurnal Oseanografi, 2(2):151-160.

Kurniawan, R., Habibie, M.N. \& Permana, D.S., 2012. Kajian Daerah Rawan Gelombang Tinggi di Perairan Indonesia, Jurnal Meteorologi dan Geofisika, 13(3):201-212.

Kusmanto, E. \& Setyawan, W.B., 2013, Arus Rip di Perairan Pesisir Pangandaran, Jawa Barat, Indonesian Journal of Marine Science, 18(2):61-70.

McCarrol, R.J., Brander, R.W., MacMahan, J.H., Turner, I.L., Reniers, A.J.H.M., Brown, J.A., Bradstreet, A. \& Sherker, S., 2014, Evaluation of Swimmer Based Rip Current Escape Strategies, Natural Hazards, (71):1821-1846.

Patra, S.K., Pradhan, U.K., Mishra, P. \& Mohanty, P.K., 2014, Wave Height
Selection Criteria for Beach Hazard Rating and its Implication Along South Orissa, East Coast of India, International Journal of Environmental Sciences, 4(5):1023-1030.

Pereira, P.S., Calliari, L.J. \& Lelis, R.J.F,2004, Frequency Beach Profile Monitoring: Implications in Beach Safety at Cassino Beach, Southern Brazil, Journal of Coastal Research, 39:908-911.

Sandro, R., Purba, N.P., Faizal, I. \& Yuliadi, L.P.S., 2018, Rip Current at Pangandaran and Palabuhan Ratu, Global Scientific Journal, 6(6):202-212

Setyawan, W.B., Kusmanto, E., Ulumuddin, Y.I., Hasanudin, M., Natsir, M.S. \& Ongkosongo, O.S.R., 2011, Geomorfologi Kawasan Pesisir Teluk Parigi Kabupaten Ciamis, Propinsi Jawa Barat, Ikatan Sarjana Oseanologi Indonesia (ISOI), Jakarta.

Short, A.D. \& Hogan, C.L., 1994. Rip currents and beach hazards: their impact on public safety and implications for coastal management. Journal of Coastal Research : 197-209.

Short, A.D., 1996, The Role of Wave Height, Periode, Slope, Tide Range and Embaymentisation in Beach Classifications: a Review, Revista Chilena de Historia Natural, 69:589-604.

Sofian, I., \& Wijanarto, A.B., 2010. Simulation of Significant Wave Height Climatology Using WaveWatch III, International Journal of Geoinformatics, 6 (4):13-19.

Suciaty, F, 2018, Transformasi Gelombang Swell dan Gelombang Angin di Perairan Selat Bali, Reka Racana, 4(3):28-39.

Suharto, 2016. Studi Tentang Keamanan dan Kelelamatan Pengunjung Hubungannya dengan Citra Destinasi (Studi Kasus Gembira Loka zoo). Jurnal Media Wisata, 14(1):287-304.

Tyawati, A., 2016. Tourists' Safety of Coastal Tourism Revisited a study at Parangtritis Beach, District of Bantul, Yogyakarta Special Region, in: Proceedings of the Asia Tourism Forum. Bandung, Indonesia : 0131-0137, doi : 10.2991/atf-16.2016.20

Warton, N.M. \& Brander, R.W., 2017. Improving tourist beach safety awareness: The benefits of watching Bondi Rescue. Tourism Management, 63:187-200 
Woodward, E., Beaumont, E., Russell, P. \& MacLeod, R.2015, Public Understanding and Knowledge of Rip Currents and Beach Safety in the UK, International Journal of Aquatic Research and Education, 9(1):49-69

Yang, B., Lee, J., Hwang, J.S., Kweon, H.M. \& Lee, J.L., 2014, Quantitative Risk Assessment for Beach Drowning
Management, Journal of Coastal Research, 72:117-121.

Yudhicara, Zaim, Y., Rizal, Y., Aswan., Triyono, R., Setiyono, U. \& Hartanto D., 2013, Characteristics of Paleotsunami Sediments, A Case Study in Cilacap and Pangandaran Coastal Areas, Jawa, Indonesia, Indonesian Journal of Geology, 8(4):163-175. 